\title{
EDUKASI PEMBUATAN KERTAS pH SEBAGAI MEDIA PEMBELAJARAN DI SMAN 1 WONOSARI KLATEN
}

\section{NATURAL pH PAPER AS A LEARNING MEDIUM IN SMAN 1 WONOSARI KLATEN}

\author{
${ }^{1)}$ Akida Mulyaningtyas, ${ }^{2)}$ Alfian Eko Wahyudi, ${ }^{3)}$ Ilham Caresa Wardana \\ ${ }^{1,2,3)}$ Program Studi Teknik Kimia, Fakultas Teknik \\ Universitas Muhammadiyah Surakarta \\ Jalan A. Yani Tromol Pos 1 Pabelan Surakarta \\ Email: akida.mulyaningtyas@ums.ac.id
}

\begin{abstract}
ABSTRAK
Untuk mendukung kegiatan pembelajaran mata pelajaran kimia di SMA diperlukan praktek di laboratorium. Kegiatan praktikum tersebut bertujuan untuk mendukung para siswa dalam memahami materi yang diberikan guru di kelas. Namun banyak sekolah yang masih belum memiliki prasarana laboratorium maupun alat dan bahan yang terkait seperti misalnya kertas pH yang biasa digunakan pada praktikum asam basa pada pelajaran kimia di kelas XI. Pada dasarnya indikator larutan asam basa dapat dibuat dari berbagai macam tanaman yang ada di sekitar kita yang memiliki zat warna. Perubahan warna bunga tanaman yang dipengaruhi kondisi asam atau basa dapat dijadikan sebagai indikator larutan asam basa. Selanjutnya tanaman tersebut dapat dibuat menjadi kertas indikator pH dengan cara yang cukup sederhana. Pada kegiatan pengabdian ini, bunga kertas atau bougenville dipilih sebagai indikator alami karena dapat menghasilkan perubahan warna yang cukup jelas pada rentang pH 6-8. Kegiatan pengabdian ini dilaksanakan di SMA Negeri 1 Wonosari Klaten kelas XI IPA 2. Materi larutan asam-basa diberikan pada awal semester 2 kelas XI. Tahapan pengabdian meliputi pemberian materi larutan asam-basa dengan metode ceramah dan cara kerja pembuatan kertas pH dilanjutkan praktek langsung oleh para siswa.
\end{abstract}

Kata kunci: Kertas pH; Bunga Kertas; Asam; Basa

\begin{abstract}
In high school, chemistry as one of the science subjects requires laboratory practice to support the teaching and learning activities. The practice aims to support students in understanding the material provided by the teacher in class. However, many schools still lack of laboratory infrastructure and related devices such as $\mathrm{pH}$ paper, which is used in an acid-base practicum in chemistry in grade 11. Indicators of acid-base solutions can be made from various plants around us that have dyes. Changes in plant flower color affected by acidic or basic conditions can be used as an acid-base solution indicator. Furthermore, these plants can be made as $\mathrm{pH}$ indicator paper in a reasonably simple way. In our community service, we taught 11th-grade students how to make pH paper from natural sources. Paper flowers or bougainvillea are chosen as the natural indicator because they can produce fairly clear color changes in the $\mathrm{pH}$ range 6-8. This service was conducted at SMA Negeri 1 Wonosari Klaten class XI IPA 2. The related subject of acid-base was given at the beginning of semester 2 of grade 11. The activity was divided into three sessions, started by explaining the acid-base theory, followed by practicing making $\mathrm{pH}$ paper, and concluded by a comprehensive discussion. The students participate actively and enthusiastically during the complete sessions.
\end{abstract}

Keywords: pH Paper; Paper Flower; Acid; Base 


\section{PENDAHULUAN}

Ilmu kimia didefinisikan sebagai cabang ilmu alam yang mempelajari tentang eksistensi materi ditinjau dari segi struktur, sifat-sifat, perubahan, dan perubahan energi yang menyertai perubahan tersebut (Jespersen et al., 2012). Berdasarkan standar isi yang termuat dalam Permendiknas No. 22 tahun 2006, salah satu tujuan mata pelajaran kimia di SMA/MA adalah memperoleh pengalaman dalam menerapkan metode ilmiah melalui percobaan atau eksperimen, dimana siswa melakukan pengujian hipotesis dengan merancang percobaan melalui pemasangan instrument, pengambilan, pengolahan, dan penafsiran data, serta menyampaikan hasil percobaan secara lisan dan tertulis. Dari situ terlihat bahwa bahwa pembelajaran kimia di SMA seharusnya melibatkan percobaan atau eksperimen.

Salah satu materi di pelajaran kimia yang memerlukan eksperimen adalah asam-basa (Utami et al., 2009). Eksperimen yang dilakukan tergolong mudah, misal titrasi asam basa, namun memiliki dampak positif pada pemahaman siswa akan materi tersebut. Sampai pada tingkat universitas, titrasi masih digunakan sebagai salah satu metode analisis kuantitatif. Sarana yang diperlukan untuk mendukung eksperimen tersebut selain larutan asam dan basa adalah indikator $\mathrm{pH}$ untuk mengetahui titik ekivalen pada proses titrasi asam basa.

SMAN 1 Wonosari yang terletak di Desa Boto Kecamatan Wonosari Kabupaten Klaten memiliki keterbatasan sarana belajar mengajar. Berdasarkan informasi dari website yang dikelola sekolah, SMA tersebut hanya memiliki satu perpustakaan dan satu ruang laboratorium komputer sehingga bisa disimpulkan bahwa proses belajar mengajar yang membutuhkan kegiatan praktikum tidak berjalan dengan semestinya. Keterbatasan sarana laboratorium di SMAN 1 Wonosari Klaten berdampak pada rendahnya tingkat pemahaman mata pelajaran ilmu termasuk kimia yang dibuktikan dengan rata-rata nilai ujian nasional kimia hanya mencapai 54,7 pada tahun 2017.

Salah satu mata praktikum kimia kelas XI adalah asam basa (Priambodo, Nuryadi, \& Sutiman, 2009). Kegiatan ini termasuk sederhana dan dapat dilakukan di kelas dengan sarana dan prasarana yang minimalis.

Metode yang paling mudah dan murah untuk mengukur $\mathrm{pH}$ adalah menggunakan larutan indikator atau kertas $\mathrm{pH}$ yang bekerja pada kisaran $\mathrm{pH}$ tertentu. Dalam hal ini, tersedianya kertas $\mathrm{pH}$ merupakan hal yang sangat penting. Namun seringkali sekolah tak dapat mengadakan kertas $\mathrm{pH}$ karena ketidaktersediaan biaya. Sejatinya, kertas $\mathrm{pH}$ dapat dibuat dari berbagai tanaman yang memiliki kandungan zat warna tertentu. Untuk itu perlu pengetahuan yang memadai untuk membuat kertas $\mathrm{pH}$ sebagai ganti kertas lakmus atau kertas indikator universal.

Indikator asam basa bersifat subyektif. Perubahan warna tergantung pada titik ekivalen yang dicapai pada $\mathrm{pH}$ tertentu. Bahan-bahan kimia non alam yang biasanya digunakan sebagai indikator sejatinya dapat digantikan dengan bahanbahan yang diperoleh dari sekitar.

Semua bahan kimia yang memiliki perubahan warna yang nyata pada campuran reaksi analit dan titran yang sangat dekat ke titik ekivalen dapat 
digunakan sebagai indikator. Pewarna alami dan pigmen yang ada pada tanaman dapat menunjukkan perubahan warna yang dipengaruhi oleh $\mathrm{pH}$.

Beberapa senyawa organik dan anorganik berperan dalam sifat warna bagian tanaman antara lain flavonoid, flavonol, flavonoid terasilasi, antosianin, quinine, imine, polymethine, napthaquinone, anthraquinonoid, indigoid, dihidropiran, diarilmetan, dan karoten. Senyawa-senyawa tersebut menunjukkan warna berbeda dalam kisaran $\mathrm{pH}$ berbeda, sehingga dapat diterapkan untuk digunakan sebagai indikator alami (Kapilraj, Keerthanan, \& Sithambaresan 2019; Agrawal, et al., 2011).

Pada pengabdian ini dipilih bunga kertas (Bougainvillea glabra) sebagai bahan dasar indikator yang hendak dibuat kertas pH-nya. Bunga tanaman ini mengandung betalain yaitu pigmen tumbuhan yang memberi warna kuning, jingga, merah, dan ungu pada bagian daun dan buah. Salah satu contohnya adalah betasianin senyawa yang larut dalam air dan memberi warna merah-ungu (AbarcaVargas \& Petricevich, 2018).

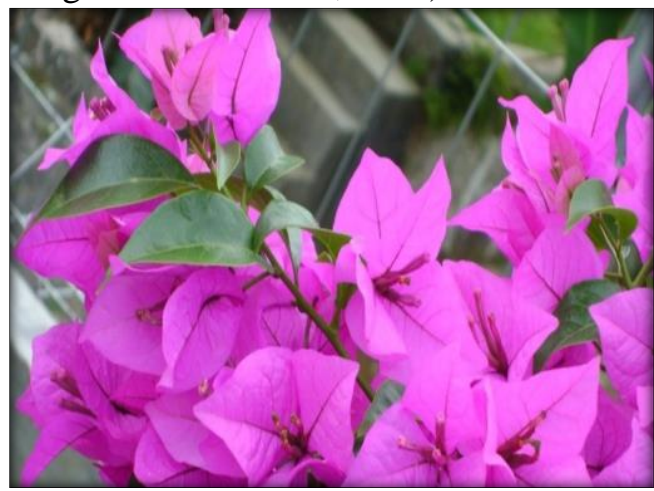

Gambar 1. Bunga kertas

Pelaksanaan pengabdian ini dilakukan pada bulan Januari, yaitu dua hari masuk sekolah setelah liburan semester gasal. Hal tersebut dikarenakan materi asam-basa diberikan pada semester genap minggu pertama sehingga diharapkan ilmu yang diperoleh pengabdian ini masih segar dalam ingatan siswa ketika materi tersebut diberikan di kelas.

Tujuan utama dari pengabdian ini adalah mengatasi permasalahan ketidaktersediaan biaya untuk melengkapi sarana dan prasarana laboratorium di SMAN 1 Wonosari Klaten. Siswa dan guru mampu membuat kertas $\mathrm{pH}$ dari bunga kertas dan menggunakannya dalam percobaan mata pelajaran kimia. Selain itu agar siswa dan guru terbuka wawasannya untuk mencoba berbagai jenis tanaman di sekitar yang dapat dimanfaatkan sebagai indikator asam basa. Selanjutnya dengan bekal dan kreatifitas yang dimiliki, siswa berinisiatif mengikuti lomba ilmiah dengan memanfaatkan pengetahuan pembuatan kertas $\mathrm{pH}$ dari bahan alam.

\section{METODE}

Ada dua metode yang digunakan dalam pengabdian masyarakat ini, yaitu metode ceramah dan pelatihan.

Mula-mula diadakan wawancara kepada siswa untuk mengetahui sejauh apa mereka mengenalasam basa. Kemudian siswa diberi ceramah tentang materi asam basa sesuai dengan tujuan pembelajaran materi tersebut. Isi ceramah meliputi pengertian asam dan basa, contoh larutan asam dan basa di sekitar kita, $\mathrm{pH}$ larutan dan indikator $\mathrm{pH}$.

Selanjutnya adalah pembuatan kertas $\mathrm{pH}$ dari ekstrak bunga kertas. Bahan yang diperlukan adalah bunga kertas 10 buah, kertas saring, alkohol $96 \%$ dan air. Alat yang diperlukan adalah mortar, Erlenmeyer $200 \mathrm{ml}$, kertas saring, dan corong. Cara pembuatan kertas $\mathrm{pH}$ adalah sebagai berikut:

1. Bunga dihaluskan dengan mortar.

2. Direndam dengan alkohol $96 \%$ supaya didapatkan ekstraknya.

3. Ekstrak disaring dengan kertas saring. 
4. Kertas dipotong sesuai kebutuhan dan direndam dalam ekstrak selama 10 menit.

5. Kertas dieringkan.

6. Dilakukan pengujian dengan larutan asam dan basa.

Sebagai larutan asam dan basa dapat digunakan larutan asam dan basa sintetis seperti larutan encer $\mathrm{HCl}$ dan $\mathrm{NaOH}$ atau bahan-bahan yang ada dalam kehidupan sehari-hari seperti cuka, larutan sabun, dan asam sitrat.

\section{HASIL DAN PEMBAHASAN}

Pengabdian ini memberikan hasil yang cukup menggembirakan. Di awal acara, dari wawancara sederhana di kelas diketahui bahwa $87,5 \%$ siswa belum mengenal tentang larutan asam dan basa secara tepat. Terbukti dengan bahwa tidak ada siswa yang menjawab pertanyaan tentang pengertian larutan asam dan basa. Materi ceramah membuka wawasan mereka tentang larutan asam dan basa, terutama karena isi materi termasuk contoh-contoh asam dan basa dalam kehidupan sehari-hari.

Pada tahap selanjutnya, siswa diajak bersama-sama membuat kertas $\mathrm{pH}$. Sesudahnya kertas $\mathrm{pH}$ dicobakan pada berbagai larutan asam dan basa yang telah tersedia. Siswa mengamati perubahan warna yang terjadi dan mengambil kesimpulan tentang sifat larutan asam atau basa. Sebagai pembanding digunakan kertas lakmus. Selain itu, siswa juga mencoba menguji larutan asam dan basa dengan kertas $\mathrm{pH}$ dari beberapa jenis tanaman lain yaitu kulit buah naga dan kol ungu yang telah dipersiapkan terlebih dahulu. Tujuannya adalah agar wawasan siswa semakin terbuka dan kreatif.

Sesi terakhir adalah diskusi tentang materi dan percobaan. Siswa terlihat sangat antusias dan menyerap materi dengan efektif. Terbukti dari 10 pertanyaan tentang asam dan basa dapat dijawab oleh $87,5 \%$ siswa. Selain itu mereka juga banyak bertanya yang menunjukkan ada antusiasme yang tinggi terhadap materi asam dan basa.

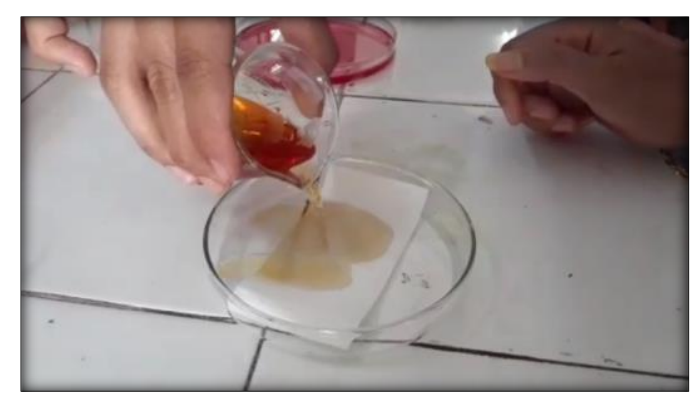

Gambar 2. Proses pembuatan kertas pH.

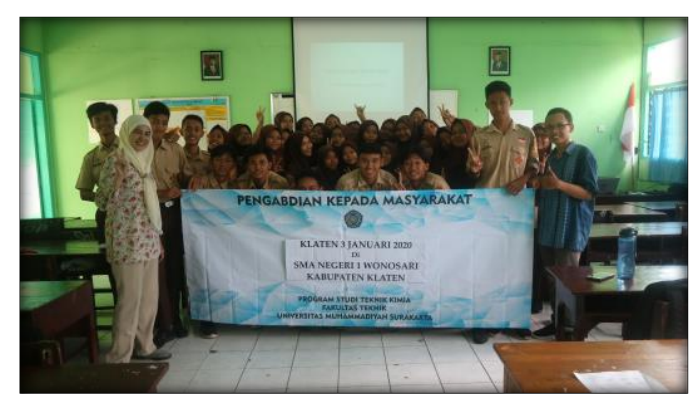

Gambar 3. Kebersamaan siswa, dosen dan mahasiswa dalam acara pengabdian masyarakat.

\section{SIMPULAN}

Pelaksanaan pengabdian yang telah dilakukan di SMA Negeri 1 Wonosari Klaten berjalan lancar dan efektif. Para guru dan siswa menyambut baik dengan adanya percobaan asam basa. Siswa antusias dan aktif dalam kegiatan praktikum. Mereka juga banyak bertanya dan ingin tahu lebih lanjut tentang materi asam basa. 


\section{DAFTAR PUSTAKA}

Abarca-Vargas, R., Petricevich, V.L. (2018). Bougainvillea Genus: A Review on Phytochemistry, Pharmacology, and Toxicology. Evidence-Based Complementary and Alternative Medicine, Article ID 9070927

https://doi.org/10.1155/2018/907092 $\underline{7}$

Agrawal, S., Raj, N.R., Chouhan, K., Raj, C.N., Jain, S., \& Balasubramaniam, A. (2011) Isolation of herbal acid-base indicator from the seeds of Punica granatum, Journal of Chemical and Pharmaceutical Research. 3(2), 168-171.

Kapilraj, N., Keerthanan S., \& Sithambaresan, M. (2019). Natural Plant Extracts as Acid-Base Indicator and Determination of Their pKa Value. Journal of Chemistry, Article ID 2031342 https://doi.org/10.1155/2019/203134 $\underline{2}$

Peraturan Menteri Pendidikan Nasional Nomor 22 Tahun 2006 Tentang Standar Isi Untuk Satuan Pendidikan Dasar dan Menengah

Priambodo, E., Nuryadi, Sutiman (2009) Aktif Belajar Kimia untuk SMA dan MA Kelas XI, Buku Sekolah Elektronik, Pusat Perbukuan, Departemen Pendidikan Nasional

Utami, B., Saputro, A.N.C., Mahardiani, L., Yamtinah, S., Mulyani, B. (2009) Kimia 2 Untuk SMA/MA Kelas XI, Program Ilmu Alam, Buku Sekolah Elektronik, Pusat Perbukuan, Departemen Pendidikan Nasional 